\title{
EL SISTEMA DE DISTRIBUCION DE COMPETENCIAS ENTRE EL ESTADO Y LAS COMUNIDADES AUTONOMAS (*)
}

\author{
$353.075(46)$
}

\author{
por \\ Tomás-Ramón Fernández \\ Catedrático de Derecho administrativo. \\ Rector de la Universidad Nacional de Educación a Distancia
}

SUMARIO: I. INTRODUCCION.-II. EL NIVEL MINIMO DE COMPETENCIAS COMUNITARIAS DEL ARTICULO 148.-III. LAS COMPETENCIAS EXCLUSIVAS DEL ESTADO SEGUN EL ARTICULO 149, 1.-IV. LAS COMPETENCIAS RESIDUALES.-V. LAS COMPETENCIAS CONCURRENTES O COMPARTIDAS.-VI. DELEGACION Y TRANSFERENCIA DE COMPETENCIAS ESTATALES.-VII. PROBLEMAS DE CARACTER GENERAL: LA DEFINICION DEL CONCEPTO DE MATERIA.-VIII. EL PROBLEMA DE LA POTESTAD LEGISLATIVA DE LAS COMUNIDADES AUTONOMAS: 1. LA LEGISLACION PLENA O EXCLUSIVA. INTERPRETACIONES POSIBLES. 2. LA LEGISLACIÓN CONCURRENTE. 3. LA INSERCIÓN DE LAS LEYES Y REGLAMENTOS REGIONALES EN EL ORDENAMIENTO GENERAL DEL ESTADO. LOS PRINCIPIOS DE JERARQUIA Y COMPETENCIA.-IX. LAS COMPETENCIAS DE LOS ENTES LOCALES EN LA ENCRUCIJADA ESTADO-COMUNIDADES AUTONOMAS. $-X$. CONSIDERACIONES FINALES.

$\left({ }^{*}\right)$ Texto de la conferencia pronunciada por el autor en la Facultad de Derecho de la Universidad Central de Barcelona el 25 de enero de 1979. 


\section{INTRODUCCION}

El consenso logrado inicialmente en el seno de la Ponencia constitucional ha conseguido convertir en norma constitucional vigen. te un sistema de distribución de competencias entre el Estado y las Comunidades autónomas que no satisface a nadie, ni a políticos ni a expertos, que no responde a ningún molde conocido, que no se ajusta ni al esquema teórico del Estado federal ni al del Estado regional, que carece de la imprescindible claridad y que ya desde ahora se revela claramente insuficiente para garantizar unas relaciones razonables entre los sujetos en presencia.

Es cierto que el problema a resolver no era nada fácil. No hay inconveniente en admitir tampoco que su dificultad intrínseca desde el punto de vista teórico se veía acrecentada notablemente hic et nunc por la diversidad de las cuestiones implicadas. Como observa Oscar AlzaGa en sus "Comentarios a la Constitución", "de un lado estaba el viejo problema de integración nacional de los pueblos vasco y catalán en ese gran colectivo que es España, y de otro, una euforia autonomista generalizada por casi toda España, que en alguno de sus aspectos recuerda el sarampión federalista de la Primera República», y ambos capítulos de problemas encerraban a su vez cuestiones políticas de alcance muy distinto, todo lo cual aconsejaba «dar con un Título VIII capaz de de albergar el Estado que demandaban las fuerzas políticas más solventes de Cataluña, capaz de ofrecer al País Vasco unas cotas de autogobierno muy elevadas, válido igualmente para atribuir las dosis de poder descentralizado que requiriesen ciertas Regiones y a la vez capaz de servir de senda para aquellas zonas de nuestra geografía sin vocación histórica autonómica y que si marchan por ese camino lo harán razonablemente con lentitud y muy de la mano de un poder central de que siempre se han sentido partícipes. Por tanto, la solución política pasaba por un Título que ofreciese un cuadro apto para ritmos y velocidades distintas, según las necesidades, un abanico de competencias confiables a las Comunidades autónomas que se podría abrir o cerrar a la medida de cada caso, dentro - claro está- siempre de unos límites. Dicho en otros términos, este Título es el intento de ofrecer un esquema general de caucho en el que quepa un traje a la medida de las pretensiones autonomistas de cada uno de nuestros 
pueblos, con una velocidad de confección del mismo también variable en atención de las urgencias que plantee cada caso y, en suma, del interés general».

Todo este cúmulo de dificultades —que no por ser nuestras son mayores ni diferentes de las que tuvieron que resolver los constituyentes italianos en 1947, o de las que afrontan hoy Bélgica y el Reino Unido- no justifica en absoluto un sistema tan carente de virtudes técnicas, tan inútilmente complejo, tan confuso y de tan difícil interpretación como el que contribuyen a formar los artículos 148,149 y 150 en lo que se refiere al concreto tema cuyo análisis es objeto de estas páginas.

A continuación intentaremos desentrañar el sistema analizando por separado cada una de sus piezas, ya que el desorden y la confusión que caracteriza el conjunto normativo formado por los tres preceptos en cuestión desaconsejan la utilización de cualquier otro método de análisis y obligan a apoyar éste, en una primera fase, sobre una base fundamentalmente descriptiva.

\section{EL NIVEL MINIMO DE COMPETENCIAS COMUNITARIAS DEL ARTICULO 148}

Dejamos a un lado por carecer en este momento de interés para nuestro tema el problema de la división en dos etapas sucesivas del proceso autonómico, fórmula con la que pretenden satisfacerse las preocupaciones de los constituyentes en orden al ritmo de la transformación interna del Estado, para centrar la atención en el análisis del cuadro de competencias que la Constitución quiere garantizar, como mínimo, a cualquiera de las Comunidades autónomas que puedan constituirse.

La frase clave a analizar es, precisamente, la que encabeza el propio artículo 148:

«Las Comunidades autónomas podrán asumir competencias en las siguientes materias .

De la frase en cuestión destaca lo siguiente:

En primer lugar, que la Constitución ha renunciado a establecer un contenido fijo de materias y ha dejado a cada Comunidad autónoma en libertad para asumir las que tenga por convenientes 
dentro de la lista que el artículo 148 contiene. Serán, pues, los Estatutos de cada Comunidad los que acotarán definitivamente el campo de acción de las mismas (artículos 147, 2, d), y 149, 3).

Este planteamiento, al que no pueden formulársele reproches desde el punto de vista técnico, constituye, sin embargo, una cautela que, muy posiblemente, resultará inútil en la práctica. Lo realmente difícil en muchas zonas del país va a ser conseguir el acuerdo político necesario para poner en pie a una Comunidad autónoma superando dentro del plazo previsto en la Constitución los requisitos exigidos al efecto. Conseguido este acuerdo, es inimaginable que los protagonistas de la escena política regional se retranqueen de la línea que marca el artículo 148 y se reduzcan por su propia voluntad a un ámbito competencial menor.

La dinámica política actual indica claramente lo contrario, esto es, que todos los órganos preautonómicos intentarán en lo posible alcanzar las cotas de autonomía que asegura el artículo 151, lo que se comienza a llamar ya el «Estatuto largo» propio de la teórica segunda etapa del proceso de transformación.

Al margen de esto hay una segunda cuestión a destacar, y es la siguiente: el artículo 148 configura una facultad de las Comunidades autónomas que va referida a "competencias en las siguientes materias». Es decir, en el pensamiento de los constituyentes está la idea de que las Comunidades no asuman todas las competencias de todas las materias, sino sólo una parte de las competencias en cada materia que deseen abordar. Se piensa, pues, no en bloques de materias, en transferencias orgánicas según la terminología italiana, sino en transferencias puntuales de carácter, por lo tanto, parcial.

Àsí lo ha subrayado AlzAGA en sus "Comentarios», aunque utilizando una terminología -competencias compartidas o compartibles- que puede resultar equívoca.

Para evitar todo posible equívoco conviene pronunciarse a este respecto con la máxima precisión posible. A estos efectos, es necesario indicar lo siguiente:

En primer término, que cualquiera que haya sido el propósito de los constituyentes, es lo cierto que las Comunidades podrán recabar, a través de sus Estatutos, la materia entera. Bastará para ello que en dichos Estatutos incluyan la expresión atodas las competencias en materia de». Si así lo hacen, su posición podrá suscitar más o menos dificultades desde el punto de vista político, pero será irreprochable desde el punto de vista jurídico. 
En segundo término, que, cualquiera que sea la actitud que las distintas Comunidades adopten, el reparto de competencias no abocará a un sistema de competencias compartidas, a menos que las propias Comunidades lo quieran.

En efecto, dejando a salvo este último supuesto, que hay que admitir como mera hipótesis, la parcelación por vía estatutaria de una materia entre el Estado y una Comunidad autónoma comporta la asignación a aquél y a ésta de unas determinadas competencias que, a partir del momento mismo de la promulgación del Estatuto, pasarán a ser, en principio, competencias propias y exclusivas de uno o de otra, no competencias compartidas. Lo que puede eventualmente quedar compartido es la materia como tal; las competencias asumidas en el Estatuto por la Comunidad dentro de una determinada materia serán competencias exclusivas de la Comunidad en cuestión y, por lo tanto, el Estado no podrá ejercerlas, so pena de inconstitucionalidad.

Un ejemplo aclarará la cuestión. En materia urbanística, el campo puede repartirse de mil formas. Supongamos, sin embargo, que el reparto se hace asumiendo la Comunidad autónoma solamente la ejecución y gestión del planeamiento. En tal caso, el Estado tendrá competencia exclusiva en lo que se refiere a la formulación y aprobación del planeamiento, y la Comunidad, a su vez, será exclusivamente competente en lo que respecta a la gestión y ejecución de los planes aprobados por el Estado.

No hay, pues, concurrencia alguna, porque la idea de competencia compartida o concurrente exige la previa definición de una zona común de actuación en la que las dos autoridades pueden moverse simultáneamente, según las reglas o criterios que se fijen (simple prioridad en el tiempo, distinción entre "principios»-Estado- y «detalle» - Comunidad-, existencia o inexistencia de razones de índole superior o de interés nacional, etc.).

Todo ello, claro está, según antes se ha indicado, salvedad hecha de que los propios Estatutos de las Comunidades resolvieran expresamente configurar una materia como compartida, lo cual es perfectamente posible desde un punto de vista constitucional $\mathrm{y}$, quizás, incluso, no fuera indeseable políticamente en algún caso. La posibilidad queda, no obstante, en manos de las Comunidades, no del Estado.

Una última observación es preciso hacer aquí en cuanto a este tema. Como ya hemos dicho, la Constitución parece pensar en un 
reparto puntual de competencias entre las Comunidades de Derecho común, más que en la fórmula de los traspasos orgánicos de materias en bloque. Hemos dicho igualmente que ese propósito puede no verse convertido en realidad, sin embargo, si las Comunidades optan por la organicidad de los traspasos.

A pesar de ello, sería ingenuo pensar que el propósito de los constituyentes no vaya a ejercer ninguna influencia en el desenvolvimiento futuro del tema. Debe tenerse presente que ésta no es cuestión que puedan zanjar ni la Constitución ni los Estatutos, que son solamente puntos de partida de un proceso de duración indefinida, simples reglas de convivencia y que, en definitiva, la vida colectiva a la que dichas reglas abren paso es la que, con su concreta dinámica, irá planteando en concreto los problemas y propiciando en cada caso las correspondientes soluciones. Si a ello se une la propia indefinición de lo que por materia ha de entenderse, la inexistencia de fronteras "físicas» entre las distintas materias $y$, por qué no decirlo, la inercia centralizadora que resulta, no sólo ni principalmente siquiera, de la oposición o de la falta de fe en el proceso de transformación pluralista del Estado, sino de las propias estructuras profundas de la sociedad industrial, no es posible descartar que ese propósito reobre sobre las normas e impulse en un sentido limitativo su futura interpretación.

Sobre todo ello, que es tema capital, volveremos luego, porque la problemática que el tema encierra es común a todo tipo de Comunidades.

\section{LAS COMPETENCIAS EXCLUSIVAS DEL ESTADO SEGUN EL ARTICULO 149, 1}

La segunda de las técnicas que la Constitución emplea, después de garantizar a las Comunidades autónomas un nivel de competencias mínimas, es la delimitación de un ámbito reservado exclusivamente al Estado en el que, ni ahora ni nunca, podrán entrar las Comunidades autónomas.

Esta técnica, que se plasma en el artículo 149, 1, es típica de los esquemas federales y tiende a configurar las competencias del Estado como competencias de atribución y, correlativamente, las de las Comunidades autónomas como competencias de Derecho común. En esta línea lógica —que es, justamente, la contraria a la 
de la Constitución italiana, cuyo artículo 117 atribuye a las Regiones unas concretas competencias y deja el resto del campo a la República- sería forzoso concluir que los poderes comunitarios o regionales, en cuanto poderes de Derecho común, estarían dotados de una inicial virtud expansiva, de la que no gozarían los poderes estatales como simples potestades de atribución que son.

Esta tesis es, sin embargo, muy discutible, como luego veremos, porque, en su afán de encontrar y mantener un consenso básico, las fuerzas políticas que han protagonizado el proceso constituyente han mezclado elementos de muy diversas procedencias superponiendo a la lógica de una determinada institución la de otra distinta, de todo lo cual viene a resultar un híbrido que, posiblemente, ha dejado muy tranquilos a los políticos, aunque sólo sea porque les ha permitido aplazar los problemas, pero que a los juristas, que por formación y oficio somos y tenemos forzosamente que ser más rigurosos, nos resulta extremadamente desconcertante.

\section{LAS COMPETENCIAS RESIDUALES}

El artículo 149, 3, precisa -y ésta es la tercera pieza del sistema- que «las materias no atribuidas expresamente al Estado por esta Constitución podrán corresponder a las Comunidades autónomas en virtud de sus respectivos Estatutos". Ahora bien, si los Estatutos no reclaman expresamente alguna o algunas de estas materias, la competencia sobre las mismas corresponderá al Estado.

El precepto es sólo aplicable hoy por hoy a las que, para entendernos, vamos a llamar Comunidades especiales (las que plebiscitaron en el pasado Estatutos de Autonomía -eufemismo ridículo e inútil que recuerda el del cumplimiento de las previsiones sucesorias con el cual la Ley Orgánica del Estado de 1967 quiso evitar decirle al General Franco que un día habria de morirse, como todos los humanos- y las que consigan ahorrarse la etapa de rodaje del artículo 148,1 , por la vía que ofrece el 151,1 ), pero lo será mañana para todas, por lo que hay que reconocerle un valor general y definitorio y analizarle como tal.

Al Estado pertenecen, pues, las materias residuales, en las que se incluyen las que los Estatutos no citen expresamente, ya sea por voluntad $\mathbf{u}$ olvido, $\mathrm{y}$ todos los nuevos sectores competenciales, todas las nuevas áreas de responsabilidad del poder público que la 
dinámica social pueda hacer surgir en el futuro, aspecto éste nada despreciable por cierto (piénsese, por ejemplo, que toda la problemática del medio ambiente y de la ecología era sencillamente desconocida en el panorama comparado hasta la presente década).

Esta atribución al Estado de las materias residuales tiene, sin embargo -es importante notarlo-, un valor temporal, ya que la única frontera constitucional insalvable es la del artículo $149,1$. Quiere esto decir que no hay obstáculo alguno de orden constitucional para recabar mañana por la vía de la reforma del Estatuto correspondiente lo que se ha abandonado $u$ olvidado hoy.

En cualquier caso, tiene también suma importancia subrayar que la atribución al Estado de las competencias residuales responde a la lógica institucional característica del Estado regional, pero que de esta regla no cabe deducir nada en contra de la idea antes extraída del hecho del acotamiento de un ámbito competencial exclusivo del Estado en orden a la vis expansiva que hay que reconocer, en principio, a las competencias comunitarias como competencias de Derecho común.

Se trata de cuestiones, próximas sí, pero diferentes, como vamos a ver más claramente a medida que progresemos en el análisis de las restantes piezas del sistema.

\section{LAS COMPETENCIAS CONCURRENTES O COMPARTIDAS}

¿Existen competencias compartidas o concurrentes? En principio, dado el esquema de distribución de competencias que la Constitución establece, la respuesta debería ser negativa, abstracción hecha de lo dispuesto en los números 1 y 3 del artículo 150.

En efecto, como ya hemos visto, la Constitución ha huido del esquema habitual de reparto de competencias que se utiliza en los Estados de estructura pluralista, federales o regionales, esquema que consiste en la delimitación de tres campos distintos: competencias propias del Estado, competencias exclusivas de las Comunidades infraestatales y competencias concurrentes.

En lugar de este esquema, nuestra recién promulgada Constitución ha delimitado, como ya sabemos, un ámbito de competencias exclusivas del Estado -artículo 149, 1-, permitiendo que los Estatutos de las Comunidades autónomas recaben todas las demás (en una o dos fases, cuestión de la que puede prescindirse 
ahora), lo que supone que, a partir de la promulgación de los Estatutos, todas las materias estarán distribuidas entre el Estado y las Comunidades y asignadas a aquél o a éstas con carácter exclusivo cualesquiera que sean los términos del reparto.

Teóricamente, por lo tanto, no quedan vacíos entre ambas zonas, es decir, no existe una zona común al Estado y a las Comunidades autónomas, puesto que la propia Constitución dispone que las competencias residuales (es decir, las no mencionadas en el artículo 149, 1, y no recabadas expresamente por los Estatutos) serán estatales (artículo 149, 3).

¿Cómo se entiende entonces el principio, que se formula en el artículo 149, 3, de la prevalencia del Derecho estatal sobre el Derecho comunitario en caso de conflicto? En realidad, no tiene por qué haber conflicto de normas porque los ámbitos materiales están separados y, por lo tanto, en pura teoría no tienen por qué concurrir normas de origen diferente sobre un mismo punto.

Cabría pensar, en principio, que la regla de prevalencia del Derecho estatal juega en relación a las eventuales zonas de concurrencia que puedan crearse al amparo del artículo 150, pero no parece que ésta pueda ser la interpretación, pues, en primer lugar, el concepto mismo de Ley marco que en dicho precepto se maneja lleva en sí la superioridad lógica de la Ley estatal a cuyos principios debe ajustarse por hipótesis la Ley regional, lo cual, obviamente, hace innecesario reiterar la regla; en segundo lugar, debe tenerse presente que la regla en cuestión está situada en el artículo 149 y que, por lo tanto, su juego propio habrá de desenvolverse en el ámbito de dicho precepto y no fuera de él.

Tampoco puede explicarse la regla a la que nos referimos en relación a los conflictos fronterizos, porque en tales casos no se produce propiamente concurrencia de normas, sino, más bien, invasión por una de ellas del campo atribuido a otra, so pretexto de una confusa delimitación de la frontera. En un supuesto de este tipo, lo que habrá es un problema de inconstitucionalidad de la norma invasora, cuya decisión exigirá, por supuesto, al Tribunal Constitucional una operación previa de deslinde, pero eso es algo totalmente diferente de decidir qué norma de entre dos, que en principio son aplicables por razón de la materia, debe prevalecer.

Sólo queda, pues, una posibilidad, y esa posibilidad parte de admitir la existencia de zonas de concurrencia, de competencias compartidas, que resultan, en efecto, del propio texto constitucional, 
aunque no hayan sido deslindadas formal y expresamente como tales por el mismo.

Este es el caso de la cultura, campo en el que el artículo 149, 2, reconoce competencia al Estado, sin perjuicio de que ésta sea una materia típicamente regional (artículo 148, 1, 17).

Este es el caso, también, de la legislación procesal, materia de competencia exclusiva del Estado (artículo 149, 1, 6. ${ }^{\circ}$ ), "sin perjuicio de las necesarias especialidades que en este orden se deriven de las particularidades del Derecho sustantivo de las Comunidades autónomas».

Este es el caso igualmente de la legislación civil (artículo 149, $\left.1,8^{\circ}\right)$; de la investigación científica, a la que se alude en el artículo $149,1,15$, como competencia exclusiva del Estado y en el artículo $148,1,17$, como competencia de las Comunidades autónomas; de la pesca y, en general, de todas aquellas materias que el artículo 149 enumera como exclusivas del Estado, añadiendo un "sin perjuicio» - las expresiones «bases», «legislación básica» o "normas básicas».

Nuevamente nos encontramos, pues, con algo que no se dice abiertamente, pero que se deduce, lo cual es siempre fuente de problemas.

No es éste el momento de estudiar aquí la problemática de las leyes marco o normas-principios, que es amplia y compleja. Hay que decir, sin embargo, que esta consagración indirecta y no frontal de una zona de competencias concurrentes se ha traducido en la falta de mecanismos adecuados de ensamblaje entre la Ley estatal y la Ley regional y, en concreto, de una definición general de los respectivos niveles de normación.

Esta ausencia de principios generales para ordenar la concurrencia del tipo de los establecidos en el artículo 117 de la Constitución italiana (Estado: principios fundamentales de cada materia; Regiones: regulación de detalle, siempre que no contrasten con el interés nacional o con el de otras Regiones) o en el 72 de la Ley Fundamental de Bonn (que un asunto no pudiere ser reglamentado satisfactoriamente por la legislación de los Estados; que la reglamentación de un asunto por ley de un Estado pudiera afectar los intereses de otros Estados y los intereses generales, que lo requiera el mantenimiento de la unidad jurídica o económica, especialmente el mantenimiento de condiciones de vida uniformes más allá del territorio de un Estado), obliga a analizar, caso por caso, todas y cada una de las materias en las que, según el artículo 149, 1 y 2 , 
el campo competencial es común al Estado y a las Comunidades autónomas.

A continuación examinaremos, pues, aunque muy sumariamente, cada uno de estos supuestos integrantes de lo que, aunque sistemáticamente no se haya organizado asi de modo expreso, viene a resultar la zona intermedia o común.

a) Legislación procesal (artículo 149, 1, 6.․). Corresponde al Estado la regulación general y a las Comunidades autónomas la de "las necesarias especialidades que en este orden se deriven de las particularidades del Derecho sustantivo» de las mismas.

Será preciso, por lo tanto, acotar primero cuáles son las peculiaridades del Derecho sustantivo de una Comunidad y después analizar si esas peculiaridades sustantivas comportan necesariamente una especialidad en el orden adjetivo o procesal.

b) Legislación civil (artículo 149, 1, 8. ${ }^{\circ}$ ). Se deja subsistente la situación actual en lo que concierne a los Derechos forales, por lo que en este punto, contando como se cuenta con una larga y pacífica tradición de coexistencia de éstos con el Derecho civil común, no parece que puedan producirse dificultades.

c) Ordenación del crédito, banca y seguros (artículo 149, 1, 11). Al Estado se atribuye en exclusiva el establecimiento de las bases de la ordenación, esto es, de los grandes principios o principios básicos de la misma, con lo cual podría entenderse, en principio, que todo lo demás puede ser competencia de las Comunidades autónomas. Esta conclusión sería, pienso yo, muy arriesgada. Es ésta una materia que afecta sustancialmente a la unidad económica del Estado entero y no es de creer que el Estado renuncie tan simplemente a manejar por sí mismo y con carácter general todos los resortes necesarios para asegurar esa unidad.

Argumentos no le van a faltar para ello (cfr., por ejemplo, el artículo 138, 2, como límite a la potestad estatutaria). Por lo demás, y en cuanto al crédito y a la banca se refiere, debe retenerse que todo el sistema se apoya sobre la existencia del Banco de España, de los demás bancos oficiales y del organismo coordinador, que es el Consejo Superior Bancario, instrumentos todos ellos cuyo manejo exige una unidad de dirección que, una vez establecida, deja muy poco margen para la intervención de autoridades regionales.

d) Planificación general de la actividad económica (artículo $149,1,13)$. Aunque la dicción literal del artículo 149 apunta a unos términos de reparto notablemente generosos para las Comunida- 
des autónomas, puesto que sólo delimitan como competencias exclusivas del Estado "las bases y coordinación» de la planificación, hay que tener muy presente que en lo que a la elaboración del plan se refiere el artículo 131 atribuye al Estado la competencia para aprobar la correspondiente Ley y al Gobierno, en concreto, la de elaborar los proyectos necesarios, limitando la intervención de las Comunidades autónomas a suministrar a aquél las necesarias previsiones.

e) Investigación científica (artículo 149, 1, 15). El fomento y la coordinación de la investigación científica y técnica se define como competencia exclusiva del Estado por el artículo 149, pero el 148 asigna igualmente a las Comunidades autónomas funciones de fomento de la investigación. La naturaleza de la función de fomento, que consiste básicamente en estimular actividades de otros sujetos, permite sin problemas actuaciones superpuestas en una misma dirección, lo cual reduce la posibilidad de conflictos a los supuestos en que por una Comunidad autónoma se actúe en contra del cuadro general de directrices de coordinación de las distintas acciones que los órganos estatales puedan establecer.

f) Sanidad interior (artículo 149, 1, 16). Se atribuye al Estado la determinación de las bases y de la coordinación general, según el artículo 149.

El término «bases» hay que entenderlo - ya lo hemos indicado más atrás - como expresivo de un criterio de intensidad o trascendencia, es decir, como alusivo a los principios fundamentales de la regulación de una materia determinada, principios que necesariamente incorporan la determinación de las líneas generales de una cierta política. Esta interpretación de la expresión "principios fundamentales», utilizada para organizar la potestad legislativa regional en el cuadro de las leyes estatales por el artículo 117 de la Constitución italiana, es prácticamente unánime en Italia y es, por otra parte, la única posibilidad de asegurar una mínima e imprescindible coherencia de un conjunto que expresamente dice fundamentarse en la unidad. El desenvolvimiento de estos principios, así entendidos, será, pues, lo propio de las Comunidades autónomas.

«Coordinación», por su parte, es término que alude a la acción de conjuntar o sistematizar elementos diversos y que, sub specie jurídica, incorpora, según la mejor doctrina, una cierta idea de superioridad del sujeto al que esa función se atribuye sobre todos los demás o, si se quiere, de subordinación de éstos a aquél, lo que 
comporta unos determinados poderes de dirección del conjunto que sin llegar a alcanzar la intensidad propia de los poderes jẹárquicos, contribuyen a definir una relación que dista much yer ser neutral y de la que, en consecuencia, forma parte la posibilidad de impartir directrices y criterios de actuación de obligado cumplimiento para los sujetos coordinados.

Aplicando estas ideas a nuestro terreno, no es irrazonable concluir que la reserva a favor del Estado de las funciones de coordinación de un sector concreto equivale a asegurarle la posibilidad de definir y de imponer el marco general de la política sectorial.

Adaptar esa política general a las peculiares características de cada territorio parece ser, pues, lo propio de las Comunidades autónomas.

g) Seguridad Social. El artículo 149, 1, 17, reserva al Estado la legislación básica en materia de Seguridad Social, expresión ésta a la que hay que dar idéntico valor que al término «bases». Sin embargo, el hecho de que la reserva estatal se extienda al «régimen económico» de la institución en general recorta el campo teórico de actuación de las Comunidades autónomas hasta límites extremos, dada la vis expansiva que lo económico encierra dentro de sí.

h) Régimen jurídico de las Administraciones públicas y régimen estatutario de sus funcionarios (artículo 149, 1, 18).

Las «bases» de ambos, con el alcance que ya hemos precisado, corresponden al Estado.

i) Procedimiento administrativo (artículo 149, 1, 18). Se atribuye al Estado la regulación del procedimiento administrativo común, adjetivo este último que parece que habrá que interpretar como equivalente a "general», puesto que la competencia sobre los procedimientos especiales parece que debe ir arrastrada por la de la materia a la que la especialidad se refiere.

La estructura actual de la regulación del procedimiento administrativo, en la que la Ley de 1958 juega respecto de las normas especiales el papel de marco general en el que éstas han de encajarse, facilita la comprensión y el futuro juego del nuevo esquema constitucional.

Con respecto a este procedimiento común o general, la reserva a favor del Estado se exceptúa en favor de las Comunidades autónomas en lo que se refiere a «las especialidades derivadas de la organización propia de las Comunidades autónomas". El término «organización»es, pues, el eje del reparto. 
j) Contratos y concesiones administrativas (artículo 149, 1, 18). Corresponde al Estado la «legislación básica» sobre estos temas, expre ${ }^{2} n$ cuyo alcance en este caso debe ponerse en relación con la con petencia sobre las concretas materias en cuyo ámbito vayan a incidir ambos institutos.

k) Pesca marítima (artículo 149, 1, 19). En este caso, el Estado parece quedar en libertad para determinar, a través de la concreta ordenación del sector, si y cómo van a intervenir las Comunidades autónomas. Es, pues, esa ordenación del sector la que puede crear y organizar la concurrencia propiamente dicha.

l) Ferrocarriles y transportes terrestres (artículo 149, 1, 21).

El criterio de reparto es aquí territorial, como contribuye a subrayarlo el artículo $148,1,5 .{ }^{\circ}$. Como tal, el criterio es claro, aunque lógicamente necesita un complemento para asegurar los enlaces de territorio a territorio, cuestión ésta que parece razonable atribuir al Estado.

Queda también sin resolver el problema que plantea la existencia de un ente público de ámbito nacional (FEVE), bajo cuyo ámbito de responsabilidades caen, sin duda, líneas de ámbito exclusivamente comunitario. La existencia de este tipo de entes comporta una evidente inercia centralizadora. Así ha ocurrido en Italia y así ocurrirá muy probablemente en España.

il) Aguas (artículo 149, 1, 22). También aquí el criterio territorial es el eje de la partición, aunque el concepto de cuenca hidrográfica, que es el único que razonablemente puede manejarse en este caso, tiende a vaciar realmente la competencia de las Comunidades. Esa es, por otra parte, la tendencia en todos los Estados federales, tendencia que viene impulsada por el carácter básico del recurso y la necesidad de optimizar su aprovechamiento.

$m$ ) Medio ambiente (artículo 149, 1, 23). Aunque aquí se reserva al Estado igualmente la «legislación básica», la conclusión no puede ser la misma que se ha obtenido en otros casos, ya que el propio artículo 149 precisa a continuación que lo que se atribuye a las Comunidades autónomas es el establecimiento de «normas adicionales de protección», concepto éste suficientemente preciso que no exige ulteriores aclaraciones.

n) Montes y vías pecuarias (artículo 149, 1, 24). El empleo de la expresión ulegislación básica» es el criterio de deslinde, por lo que no parece preciso añadir aquí nuevos comentarios.

o) Obras públicas (artículo 149, 1, 24). El criterio básico es 
aquí el del alcance nacional o meramente regional del interés de la obra. ¿Habrá que interpretar este concepto jurídico indeterminado que es el de interés nacional en términos territoriales? Creemos que no, puesto que el precepto precisa adicionalmenté que si la realización de la obra afecta a más de una Comunidad autónoma la competencia será estatal en todo caso. Hay, pues, que estimar que el concepto de interés nacional incorpora más bien elementos cualitativos aludiendo a la importancia, alcance y trascendencia de la obra de que se trate y a la proyección de sus concretos efectos.

p) Régimen minero y energético (artículo 149, 1, 25). Se emplea aquí el término ya comentado de bases, que no requiere ahora nuevas precisiones en lo que al régimen minero se refiere.

El tema del régimen energético es, lógicamente, más problemático en este momento. Por lo pronto, en lo que a la energía eléctrica se refiere habrá que estar a lo dispuesto en el número 25 del mismo artículo.

Por otra parte, no puede olvidarse que éste es un elemento capital de todo intento de planificación, por lo que la solución vendrá condicionada necesariamente por esta vía.

q) Medios de comunicación social (artículo 149, 1, 27). Aquí la expresión "normas básicas», de alcance ya conocido, se precisa todavía más al concretar la intervención de las Comunidades autónomas al «desarrollo» (y a la ejecución) de las mismas, término que tiene igualmente un significado jurídico preciso en el seno de la teoría de las normas (doctrina del complemento indispensable).

r) Seguridad pública (artículo 149, 1, 29). En este sector, la Constitución, excepcionalmente, ha situado entre ella y los Estatutos una Ley orgánica estatal, que será la que organice la concurrencia competencial.

El carácter de Ley orgánica que tienen igualmente los Estatutos, propicia un intento de simplificación del esquema y, consiguientemente, la tesis de que el tema se resuelva sin más a través de ellos. Urgencias políticas pueden igualmente terminar consolidando esta tesis, pero el tenor literal del precepto no deja lugar a dudas respecto a la intención de los constituyentes: interponer entre Constitución y Estatutos una Ley orgánica específica.

s) Enseñanza (artículo 149, 1, 30). Aunque las aspiraciones de ciertas colectividades territoriales sean otras en esta importantísima materia, el tenor literal del número 30 del artículo 149,1 , es muy claro. Con arreglo a él, es evidente que el establecimiento de 
las «normas básicas para el desarrollo del artículo 27. de la Constitución» es competencia estatal exclusiva.

La articulación de los poderes estatales y regionales gira, pues, en torno a un binomio fácilmente identificable y manejable: normas básicas (Estado)-desarrollo (Comunidades autónomas).

t) Cultura (artículo 149, 2). La enmienda introducida a última hora por el señor LA CiERva ha convertido el campo de la cultura (inicialmente comunitario: $148,1,17$ ) en zona común para ambos órdenes de poderes, pero lo ha hecho en términos no fáciles de definir con carácter general.

Está claro, desde luego, que una de las cosas que debe hacer el Estado es facilitar la comunicación cultural entre las Comunidades autónomas. Está claro, también, que esta labor ha de desarrollarse «de acuerdo con ellas», lo que apunta a una negociación previa caso por caso y en términos jurídico-formales, muy probablemente, a la técnica de informes preceptivos y vinculantes de cada Comunidad sobre los concretos proyectos, programas o acciones a emprender con este fin que afecten a la cultura privativa de las mismas.

No creo que haya dificultad en admitir como competencia del Estado el fomento de la cultura común, es decir, de la cultura española propiamente dicha, que ninguna Comunidad autónoma estaría legitimada para obstaculizar.

Mucho más allá no puede llevarse en este momento la tarea interpretativa, dada la amplitud y variedad del concepto cultura.

Estos son los criterios específicos que en cada caso se desprenden del texto constitucional en lo que se refiere a la zona competencial común.

Sobre ellos viene a operar no para sustituirlos, sino para resolver los eventuales conflictos que no puedan solventarse con tales criterios, el principio de prevalencia del Derecho estatal que establece igualmente el artículo 149, 3.

Hay que insistir, porque el tema es importante, en que el principio de prevalencia del Derecho estatal no puede operar en primer resorte, porque ello equivaldría, ni más ni menos, a liquidar el concepto mismo de competencia compartida y a dejar en manos del Estado exclusivamente la decisión sobre todas las materias enunciadas. Sólo después de agotadas las posibilidades interpretativas inherentes a los criterios de articulación en cada caso establecidos 
por el artículo 149, 1 y 2, y normas concordantes, será, pues, lícito acudir como última ratio al principio de prevalencia que consagra el artículo 149, 3.

\section{DELEGACION Y TRANSFERENCIA DE COMPETENCIAS ESTATALES}

El artículo 150, 2, del texto constitucional (resultado, como recuerda Alzaga, de una enmienda presentada en el Pleno del Congreso por el Grupo Vasco, la Minoría Catalana y los Socialistas de Cataluña, que prosperó con el voto de Unión de Centro Democrático) establece que:

«El Estado podrá transferir o delegar en las Comunidades autónomas, mediante Ley orgánica, facultades correspondientes a materias de titularidad estatal que por su propia naturaleza sean susceptibles de transferencia o delegación. La Ley preverá en cada caso la correspondiente transferencia de medios financieros, así como las formas de control que se reserve el Estado».

Como se desprende del texto transcrito y resulta, por otra parte, de los debates parlamentarios, el alcance del artículo 150, 2, se circunscribe a introducir una técnica descentralizadora adicional capaz de ampliar en ciertos supuestos el ámbito natural de actuación de las Comunidades autónomas (es decir, el círculo competencial que, según la Constitución, les es propio y que los Estatutos de cada una terminarán de precisar), extendiéndolo, en la forma que se precise, a determinadas materias de competencia exclusiva del Estado.

Se alude, en concreto, a dos técnicas distintas («transferir o delegar» dice el precepto) - la descentralización propia y la delegación intersubjetiva-, aunque muy próximas una de otra. Desde un punto de vista general, la diferencia básica entre una y otra deriva de la diversa mecánica del traspaso competencial. En el caso de la descentralización, el traspaso o transferencia se realiza directamente por la norma, de forma que sólo otra norma del mismo o superior rango podría poner fin a ella; en el supuesto de la delegación, en cambio, el traspaso que la norma posibilita en términos generales se realiza por la Administración delegante en base a consideraciones de oportunidad cuya valoración la ha encomendado la nor- 
ma de cobertura, lo cual hace posible la revocación de la delegación en cualquier momento por razones de ese orden.

En ambos casos, el ente que realiza el traspaso retiene determinados poderes de tutela, que son a los que alude el artículo 150, 2, al remitir a la correspondiente Ley de cobertura la fijación de «las formas de control que se reserve el Estado".

No parece problemático, a la vista de los debates parlamentarios, que tanto la transferencia como la delegación requieren una Ley (orgánica) específica y que, por lo tanto, ni una ni otra podrán canalizarse a través de los Estatutos. La posibilidad de transferir o delegar está configurada por el artículo 150,2, como una facultad del Estado ("el Estado podrá»), cuyo concreto ejercicio queda, lógicamente, a su discreción.

En esta dirección apunta, por cierto, la expresión «materias de titularidad estatal que por su propia naturaleza sean susceptibles de transferencia o delegación». En rigor, no hay nada que no sea transferible por naturaleza. Por ello, hay que entender que lo que se quiere decir es que el Estado, y en su nombre el Gobierno, quedan en libertad para valorar la oportunidad y conveniencia de cada transferencia en concreto y que las Comunidades autónomas carecen de título para exigir transferencia alguna a partir de sus propios y peculiares intereses.

\section{PROBLEMAS DE CARACTER GENERAL: LA DEFINICION DEL CONCEPTO DE MATERIA}

Hasta ahora hemos llevado adelante el análisis de los preceptos constitucionales que contribuyen a delimitar los campos respectivos de actuación del Estado y de las Comunidades autónomas, aceptando sin más, como si fuera totalmente aproblemático, el empleo del término «materia» que dichos preceptos utilizan constantemente.

Sin embargo, el término en cuestión, que utiliza igualmente la Constitución italiana, dista mucho de ser absolutamente pacífico.

Sin embargo, el término en cuestión, que utiliza igualmente la Constitución italiana, dista mucho de ser absolutamente pacífico. No lo ha sido ni lo es en Italia, donde por esta vía se ha hecho efectiva una corriente jurisprudencial decididamente restrictiva de la autonomía de las Regiones. 
El problema surge, en efecto, a consecuencia de la inexistencia de una definición positiva del concepto materia, que hasta ahora no era un concepto jurídico, puesto que carecía de relevancia en este campo.

En principio, por materia debe entenderse el complejo de las actividades, oficinas, bienes, institutos jurídicos relativos a un cierto sector homogéneo $o$, en otro caso, el tipo de disciplina que concierne a tal sector o el conjunto de supuestos que están regulados en él (GIzZI). Inicialmente no puede precisarse mucho más y es por eso por lo que surgen problemas a la hora de situar institutos o actividades concretas dentro de una materia $u$ otra, problemas que no hay otro modo de resolver, llegado el caso, que a través de la intervención del Tribunal Constitucional.

Por lo que pueda tener de indicativa - y porque en este momento inicial faltan, en lo que a nuestra realidad se refiere, los datos mínimos necesarios para intentar una interpretación del concepto que ofrezca alguna garantía-, conviene hacer aquí alguna referencia a la doctrina que ha venido estableciendo la jurisdicción constitucional Italiana.

Por lo pronto, la Corte Costituzionale viene sosteniendo que la individualización de las materias debe hacerse en base a un criterio objetivo y no teleológico, con lo cual se niega, de hecho, a las Regiones la posibilidad de aplicar en su favor la doctrina de los poderes inherentes y de extender, en consecuencia, su propia competencia a finalidades conexas con el objetivo primario y nuclear de aquélla.

En esa misma línea se inscribe el viraje dado por la Corte Costituzionale a raíz de la sentencia 138/1972 en relación a su primitiva postura favorable a las transferencias orgánicas de funciones establecida a partir de la convicción de que un fraccionamiento es siempre fuente de incertidumbre y contestación.

Así, la citada sentencia 138/1972 ha afirmado que, aun cuando la Ley disponga que la transferencia debe hacerse por sectores orgánicos de materias, "deja obviamente imprejuzgado el problema relativo a la definición y al contenido de esas materias", añadiendo a continuación que «los sectores orgánicos no corresponden -0 pueden no corresponder - a la pura y simple calificación linguiística de las particulares voces empleadas en la disposición constitucional». 
Se rechaza, pues, formalmente el criterio nominalista y al propio tiempo se introduce el principio del nivel regional de interés en base al cual se opta normalmente por la más restrictiva entre las diversas interpretaciones posibles de las materias constitucionalmente atribuidas a las Regiones. La sentencia 141/1972 constituye un claro ejemplo de lo que acabamos de decir. Frente a la tesis de las Regiones de que el término «urbanística» engloba todo lo que hace referencia a la ordenación del territorio, la Corte Costituzionale ha declarado que por urbanística hay que entender sólo la actividad concerniente a la ordenación e incremento de la construcción en centros habitados, con lo que toda la problemática relativa a las bellezas naturales, el paisaje, el ambiente, los parques nacionales, etc., se considera perteneciente al Estado.

Otro ejemplo ilustrativo lo ofrece la sentencia $220 / 1972$, relativa al importante tema de los entes autónomos de ámbito nacional. La tesis de la sentencia queda perfectamente resumida en el siguiente párrafo: «Una determinada intervención organizativa del legislador estatal, calificada por su carácter de organicidad y unitariedad sobre el plano nacional, puede legítimamente sustraer a las Regiones una determinada esfera de competencia» en base al límite del interés nacional.

Los ejemplos no son trasladables sin más a nuestra realidad, pero sirven para poner de manifiesto el alcance del problema. La cuestión no acaba con la promulgación de un texto constitucional y de unos Estatutos, más bien empieza ahí. A partir de ese momento se inicia un camino largo y difícil, porque los cimientos de la centralización son muy sólidos y su sustitución progresiva plantea múltiples problemas que no es posible zanjar sobre el papel en un solo acto por muy solemne que sea la ocasión.

Quiero decir con ello que de ahora en adelante será necesaria mucha serenidad $\mathrm{y}$, sobre todo, mucha constancia, serenidad y constancia que están en el polo opuesto de la simplificación y de la capacidad de dramatización con la que habitualmente suele tratarse el tema.

Inicialmente y durante bastante tiempo nada ni nadie van a poder impedir que aparezcan continuamente interpretaciones de orientación restrictiva de la autonomía regional. Intentar descalificarlas aplicando a ellas y a sus autores el mote de centralistas no pasa de ser un desahogo y una simplificación inútiles. Esas inter- 
pretaciones vienen producidas no sólo por la inercia del pasado, sino también por la dificultad objetiva de sustituir de un golpe estructuras que tienen siglos de vida a lo largo de los cuales han ido creando interconexiones muy profundas.

Hay, pues, que ser conscientes de que la transformación de un Estado unitario y centralizado en un Estado regional es una operación de porte histórico que constituye tarea sobrada para una generación entera. Conocer las dificultades es, sin embargo, presupuesto imprescindible para poder superarlas un día. Esa es la razón de que se haya apuntado aquí este concreto problema de la definición del concepto de materia aun a sabiendas de que hoy por hoy carecemos de una respuesta adecuada.

\section{EL PROBLEMA DE LA POTESTAD LEGISLATIVA DE LAS COMUNIDADES AUTONOMAS}

\section{LA LEGISLACIÓN PLENA O EXCLUSIVA. INTERPRETACIONES POSIBLES}

He dicho en otro lugar que la Constitución ha introducido la fórmula del Estado regional de una manera vergonzante, y lo he dicho, entre otras cosas, porque el Título VIII está lleno de ambigüedades con las que se quiere servir al consenso y que, de hecho, sólo sirven a la confusión. La más escandalosa de todas estas ambiguiedades es, sin duda alguna, la que afecta al tema de la potestad legislativa de las Comunidades autónomas.

Es ésta, indudablemente, una cuestión esencial, porque es evidente que del reconocimiento de dicha potestad depende la configuración misma del Estado y la naturaleza de las autonomías sobre las que pretende articularse. En los tiempos en que vivimos, la Ley, más que norma, es el vehículo a través del cual se expresan y hacen efectivas las decisiones políticas fundamentales. La potestad de hacer leyes y, por lo tanto, de adoptar decisiones políticas de este carácter constituye por ello la línea divisoria entre la autonomía política y la mera descentralización administrativa.

Esto supuesto, resultaba obligado, si es que se quería realmente configurar un Estado regional propiamente dicho sobre la base de la autonomía política de las distintas Comunidades, empezar por reconocer a éstas de modo explícito el poder de hacer leyes, 
delimitar con precisión el ámbito de dicho poder y establecer los mecanismos adecuados para garantizar el engarce de las leyes estatales y las leyes regionales por un lado, de estas últimas entre sí y de todas ellas en el ordenamiento jurídico general.

Nada de esto se ha hecho, sin embargo, obsesionados los protagonistas de la escena política por mantener a toda costa un consenso sostenido única y exclusivamente por el temor a meneallo.

En efecto, aunque resulte escandaloso, falta un precepto que reconozca frontalmente y por derecho la potestad legislativa de las Comunidades autónomas. Me refiero, claro está, a la potestad legislativa plena o primaria, puesto que es indudable que todas las Comunidades pueden operar con normas con fuerzas de Ley en el marco de la legislación estatal de principios, ya que el artículo 150 se refiere expresamente a "todas o a alguna» de ellas.

Sólo de pasada, a la hora de diseñar el esquema organizativo de las Comunidades autónomas especiales (es decir, las que plebiscitaron en el pasado Estatutos de Autonomía y las que consigan atravesar la estrecha puerta del artículo 151, 1), se alude a esta potestad, dando por supuesta su existencia. Si van a tener en todo caso Asamblea legislativa es, naturalmente, porque se quiere que hagan leyes.

¿Y las demás Comunidades autónomas? Nada se dice al respecto en la Constitución, puesto que nada significa en este orden el que, al referirse al control de la actividad de los órganos de las Comunidades autónomas, el artículo 153, a), atribuya al Tribunal Constitucional el relativo a la constitucionalidad de sus disposiciones normativas con fuerza de ley. Si sabemos ya que las Comunidades autónomas especiales pueden hacer leyes, el precepto puede entenderse perfectamnete con referencia a ellas solamente, sin que sea necesario acudir a las demás para interpretarlo correctamente, ni tampoco posible, puesto que nada en él autoriza a pensar que las de Derecho común también puedan hacerlas. Por lo demás, el precepto citado puede ser también fácilmente entendido en relación a la potestad legislativa regional para operar en el marco de leyes estatales (artículo 150), pero esto, evidentemente, es otra cuestión distinta a la que en este momento tratamos.

Ningún precepto reconoce, ni directa ni indirectamente, a las Comunidades de Derecho común una potestad legislativa plena o exclusiva en las materias, más o menos, que en base a sus respec- 
tivos Estatutos pasen a ser de su competencia. Este silencio del texto constitucional admite, lógicamente, diversas interpretaciones.

Una optimista, que podría tener apoyo en el propósito declarado de no establecer diferencias entre las distintas Comunidades (argumento artículo 138, 2, por ejemplo).

Otra pesimista, que yo mismo he formulado en otro lugar cuando la Constitución era todavía un proyecto, en la que, desde luego, no me empeño y que, por cierto, me gustaría ver desmentida por los hechos, a saber: que los constituyentes no han querido reconocer potestad legislativa exclusiva o plena a las Comunidades de Derecho común. El texto de la Constitución admite, en efecto, una interpretación de este tenor, porque es evidente que la mención que se hace a las Asambleas legislativas como pieza necesaria de la organización de las Comunidades especiales no se ha hecho para constreñir la potestad estatutaria de éstas, dado su mayor porte y peso político específico en el proceso constituyente, sino más bien para destacar una diferencia favorable a ellas. El hecho de la supresión en el texto definitivo de la mención general a las Asambleas y de la denominación de sus productos como leyes territoriales que se contenía en el artículo 133, 1, del Anteproyecto inicial, es también explícito en este sentido.

Es posible, en fin, una tercera interpretación y es que la Cons. titución haya querido dejar en libertad a cada Comunidad de Derecho común para recabar o no esa potestad y autodotarse de Asambleas legislativas con este fin. Esta es la tesis de AlzAGA, que es congruente con la ambigüedad que los consensuantes han empleado voluntaria y conscientemente a lo largo del Título VIII en su deseo de dar gusto a todos aun a costa de no complacer a nadie.

En cualquier caso, resulta penoso que una cuestión de tamaña importancia haya quedado tan poco clara.

\section{LA LEGISLACIÓN CONCURRENTE}

Como hemos visto más atrás, hay una zona, amplia por otra parte, que es común al Estado y a las Comunidades autónomas, una zona, pues, de competencias compartidas.

En esa zona la articulación de aquél y de éstas se realiza normalmente sobre un par de conceptos cuyo alcance ya conocemos: 
legislación o normas básicas, bases por un lado (Estado) y desarrollo por otro (Comunidades autónomas).

Este par de conceptos es el característico de las leyes-marco, en el cuadro de las cuales han de operar las leyes regionales. Por aquí circula una problemática específica que no es posible desarrollar ahora en su detalle, pero que hubiera exigido algún mayor complemento normativo a nivel constitucional a fin de evitar o, en su caso, resolver dificultades fácilmente previsibles. En concreto, producir las leyes-marco ¿es un deber constitucional del Estado cuyo cumplimiento condiciona el ejercicio de la potestad legislativa regional? De cara a la inevitable transición, ¿ será posible deducir de las leyes actualmente en vigor las bases o principios fundamentales de cada regulación, de forma que las Comunidades autónomas puedan ya desde su puesta en marcha producir sus propias leyes para atender a sus peculiares circunstancias y necesidades?

Todas estas preguntas, que han polarizado en Italia la atención del Parlamento, la Corte Constitucional y la doctrina durante mucho tiempo, son difíciles de resolver aquí por falta de las pautas constitucionales necesarias.

No se plantea, sin embargo, ese problema en relación a las leyes-marco de que habla el artículo 150,1 , porque en este caso se trata de leyes que abren a las Comunidades autónomas un ámbito material que, de otro modo, les resulta ajeno e inasequible («en materias de competencia estatal», dice el precepto). Es, pues, un supuesto excepcional que se producirá sólo cuando las Cortes Generales lo acuerden y en las condiciones específicas que en cada caso concreto decidan.

Otro tanto ocurre con las leyes de armonización, otra especie del género de las leyes-marco, a las que se refiere el artículo 150, 3, sólo que aquí la técnica opera en sentido inverso, es decir, autorizando al Estado para entrar en un campo que puede ser de la competencia de las Cornunidades autónomas.

\section{LA INSERCIÓN DE LAS LEYES Y REGLAMENTOS REGTONALES} EN EL ORDENAMIENTO GENERAL DEL ESTADO. LOS PRINCIPIOS DE JERARQUIA Y COMPETENCIA

Hasta ahora, en el cuadro general de un Estado unitario y centralizado, era muy fácil explicar la vertebración del ordenamiento 
jurídico, es decir, la articulación dentro del mismo de las distintas normas que lo componen.

En efecto, el principio de jerarquía normativa resolvía satisfactoriamente el 90 por 100 de los problemas y podía pasar, y de hecho pasaba, por ser la explicación única y general.

En el vértice de la pirámide, la Constitución o las Leyes fundamentales; en un segundo nivel, las Leyes ordinarias y sus equivalentes (Leyes delegadas y Decretos-leyes); a partir de ahí los productos normativos de la Administración, es decir, los reglamentos, ordenados jerárquicamente en función de la respectiva jerarquía de los órganos y autoridades de quienes emanaban: Decretos, Ordenes acordadas por las Comisiones Delegadas del Gobierno, Ordenes ministeriales, etc. (artículo 24 de la Ley de Régimen jurídico de la Administración del Estado).

Es cierto que todavía quedaban unos "flecos" cuya inserción en el ordenamiento general no encontraba adecuada explicación en el principio de jerarquía (Ordenanzas y Reglamentos de las Corporaciones locales y normas procedentes de entes públicos dotados de autonomía: los Estatutos de las Universidades, por ejemplo), pero se trataba de algo considerado como marginal, de lo cual, por lo tanto, podía prescindirse sin grave daño.

La cuestión ha variado ahora sustancialmente. Al existir pluralidad de instancias políticas con poderes normativos autónomos, el principio de jerarquía ya no puede explicarlo todo, ni casi todo, como antes sucedía.

Junto a la Ley estatal aparecen las leyes regionales. Una y otras son leyes, es decir, productos normativos del mismo valor, situadas al mismo nivel en cuanto directamente ordenadas a la Constitución $\mathrm{y}$, por lo tanto, fuentes primarias en la misma medida.

¿Cómo se relacionan, por lo tanto, ambos tipos de leyes si están equiordenadas $\mathrm{y}$, en consecuencia, no es posible someterlas a ninguna relación jerárquica entre sí?

La pregunta está implícitamente contestada a través de las explicaciones precedentes. La Ley estatal y la Ley regional actúan en campos separados, propios y exclusivos de cada uno de los poderes políticos que la Constitución reconoce, es decir, del Estado y de las Comunidades autónomas (salvedad hecha de aquellas materias que se configuran como compartidas y en las que el juego de ambas leyes, Ley-marco estatal y Ley regional de desarrollo, responde a principios peculiares cuyo alcance ya ha quedado analizado). Jun- 
to al principio de jerarquia, que antes lo dominaba todo, ha aparecido el principio de competencia, al que corresponde explicar ahora una parte del problema.

La relación Ley estatal-Ley regional en el ámbito de las materias exclusivas de uno y otro poder es, pues, una relación de separación. Cada una es independiente de la otra en su respectivo ámbito competencial propio y ambas se ordenan jerárquicamente a la Constitución, que es la norma suprema y, en consecuencia, común a las dos.

Este principio de separación competencial, por órdenes de materias, se comunica hacia abajo a las normas de rango reglamentario que cada poder pueda producir, lo que significa, lógicamente, que una Ley regional no podrá derogar un reglamento estatal, aunque sea mayor su jerarquía, ni, viceversa, la Ley estatal podrá derogar el reglamento regional, ya que unas y otras normas operan en campos diferentes y separados.

El principio de separación explica igualmente las relaciones entre las leyes y reglamentos de una Comunidad autónoma y los de otra, aunque aquí la competencia no juegue ratione materiae, como en el caso de conflicto entre normas estatales y normas regionales, sino por razón del territorio.

En resumen, pues, el principio de jerarquía explica satisfactoriamente, de un lado, la relación con la Constitución de las leyes estatales y de las regionales $\mathrm{y}$, de otro, las relaciones respectivas entre las normas reglamentarias que se produzcan en el interior de cada uno de los campos. Entre un campo y otro, tanto de materias como de territorio, la explicación de las posibles relaciones entre las diferentes normas hay que buscarla en el principio de competencia.

Esto es, en una primera aproximación, lo que conviene resaltar a propósito de la potestad legislativa y de sus productos, de acuerdo con la nueva Constitución.

\section{LAS COMPETENCIAS DE LOS ENTES LOCALES EN LA ENCRUCIJADA ESTADO-COMUNIDADES AUTONOMAS}

La Constitución, obsesionada con el problema de la relación Estado-Comunidades autónomas y del reparto de los campos respectivos de aquél y éstas, ha olvidado por completo pronunciarse 
sobre las competencias de las entidades locales, lo cual es, sin duda, muy grave.

En efecto, de Ayuntamientos, Diputaciones y demás entidades locales se dice solamente que serán representativos, que gozarán de autonomía y que deberán disponer de medios suficientes, pero no se dice cuál va a ser su ámbito material de actuación y, menos aún, si ese ámbito de autonomía va a estar defendido tanto del Estado como de las Comunidades autónomas, cuestión ésta que entendemos capital porque, si al asfixiante centralismo -y tutela - estatal va a suceder otro centralismo y otra tutela igualmente intensas por parte de las Comunidades autónomas, es evidente que España seguirá careciendo de una Administración local digna de tal nombre.

Las alusiones al contenido de la autonomía municipal y provincial que se contienen en el texto constitucional son, en efecto, muy pobres. El artículo 137 la refiere a «la gestión de sus respectivos intereses», pero eso es tanto como no decir nada. El artículo 142, al referirse a las Haciendas locales, alude a «las funciones que la Ley atribuye a las Corporaciones locales», pero ¿qué Ley?, ¿la vigente y ahora caótica legislación de Régimen local? Del artículo 148, 1, $2 .^{\circ}$, parece desprenderse, por otra parte, que los constituyentes están pensando en la situación actual y que todo lo que pretenden modificar en ella se reduce a la transferencia a las Comunidades autónomas en los sectores que, según la legislación de Régimen local, se traspasen a aquellas de las funciones de tutela que hoy corresponden a la Administración del Estado.

La versión más optimista que puede darse de este pobre conjunto normativo sería ésta: la autonomía de los entes locales carece de una garantía constitucional precisa, o, dicho de otro modo, se trata de una garantía abstracta que no asegura el quantum de esa autonomía. Habrá de ser el legislador ordinario el que precise, frente al Estado y a las Comunidades autónomas, ese quantum de autonomía local, lo que equivale a decir que el propio legislador ordinario podrá recortar mañana lo que otorgue hoy.

La Ley de Régimen local no tiene ni siquiera el carácter de Ley orgánica (artículo 81), lo cual significa que la autonomía local queda al arbitrio de cualquier mayoría parlamentaria coyuntural.

Una última advertencia: el Régimen local cae en la zona que hemos calificado de competencias compartidas, puesto que no hay otra posibilidad de encajarlo que la que ofrece el artículo 149, 1, 18, 
que atribuye al Estado la determinación de las «bases del régimen jurídico de las Administraciones públicas y del régimen estatutario de sus funcionarios». Se trata, pues, solamente de las bases, lo que significa que la Ley de Régimen local habrá de acomodarse al esquema de las leyes-marco, que remite, como hemos visto, a una legislación regional complementaria.

De todo ello parece desprenderse una conclusión poco optimista respecto del futuro de nuestra Administración local, a la que los constituyentes parecen haber dado muy poca importancia.

\section{CONSIDERACIONES FINALES}

Hasta aquí llega un primer intento de interpretación constitucional sobre el problema más delicado, sin duda, de todos los que plantea la Constitución recién promulgada. Por ambas razones, es decir, por ser el primer intento y por tratarse de un tema enormemente delicado, debo formular aquí las obligadas reservas en cuanto a las conclusiones que se han ido perfilando a lo largo de estas páginas. Tiempo habrá - pienso- para rectificarlas o elevarlas a definitivas. No lo habrá, en cambio, para esperar a que el cuadro de datos estuviera completo, porque entre tanto el mecanismo, que ya ha comenzado a funcionar, empezará muy pronto a producir sus primeros resultados. Era, pues, necesario buscar desde ahora unas pautas para valorarlos adecuadamente. 